\title{
From Lisp Machine to language lab
}

\author{
HANK J. BROMLEY \\ Bell Laboratories, Murray Hill, New Jersey
}

and

\author{
ROBERT J. JARVELLA and INGVAR LUNDBERG \\ University of Umea, Umea, Sweden
}

\begin{abstract}
A general method is described for using a Lisp Machine to study reading as it takes place. The method involves simulating, on the machine's CRT, a moving window that passes through the text being read. The speed and direction of the window can be controlled by the reader, or test probes can be coordinated within the text viewed. The method allows reading to occur in an easily monitored environment, and the reader can respond to the material being read in a flexible manner. Suggestions for programming the Lisp Machine are provided which lead to improved overall execution speed and constancy of runtime for specific pieces of code in on-line experiments.
\end{abstract}

We describe a technique for studying the reading process. The method relies on a standard Lisp Machine both to present text to be read and to collect data on-line as the text is read. To restrict immediate vision of the text, a moving window is simulated on the computer's screen. The window then moves through the text. Two basic modes of operation are available for collecting data. One involves providing the reader with active control over window speed and, if desired, window direction. The other involves having the reader perform one or more subsidiary tasks as the text is read, and recording how and how fast the reader responds to these tasks.

Historically, a number of window systems have been developed to study reading [e.g., Dixon, 1984; Granaas, McKay, Laham, Hurt, \& Juola, 1984; Ikeda \& Saida, 1978; Just, Carpenter, \& Woolley, 1982; McConkie \& Rayner, 1975; Miller \& Jarvella, 1979 (see Jarvella, 1979); Newman, 1966; Poulton, 1962]. The present system differs from most preceding ones in two ways: It is designed to allow monitoring of on-line behavior other than eye movements or reading aloud, and it is relatively flexible. A variety of reading behaviors can be studied under a variety of viewing conditions, enabling, at least in principle, a point-to-point correspondence to be determined between the text being read and the reader's processing of the text.

\section{TEXTWINDOW}

The system, called Textwindow, is implemented in ZLisp on an LMI CADR Lisp Machine also used for study-

The work described here was performed while Hank J. Bromley was a member of the Department of Linquistics and Phonetics, University of Umea, and was supported in part by a grant from the Bank of Sweden Tercentenary Foundation to the project 'Natural Communication with Computers.' We would like to thank the principal investigator, Eva Ejerhed, for her aid and encouragement. Requests for reprints can be sent to Robert J. Jarvella, Institutionen för lingvistik, Umeå Universitet, S-901 87 Umeå, Sweden. ing parsing of natural language (see, e.g., Ejerhed \& Church, 1983). The Lisp Machine is a powerful and flexible personal computer, or scientific workstation, that has been used in artificial intelligence laboratories for a decade. Besides a keyboard, the console of the machine consists of a convertible, high-resolution display and a mouse. The Lisp Machine on which the system is implemented has four memory boards with 64K 32-bit words each. During a Textwindow experiment, a subject reads the text and any visual probes presented from the machine's display, and interacts with the screen by clicking the mouse buttons or by moving the mouse. The text appears in a paged format centered near the top of the screen.

The text is presented in a serial pass. An effect of a window moving through the text is created by defining a basic string length and adding characters periodically to one end of the string while taking them away from the other end. While the moving window proceeds through the text, a visual mask is provided over information on the current page not immediately in the window. The mask can be complete (an otherwise blank screen) or something more language-like which provides word length or graphic contour features from the text surround. Extra time is provided at carriage returns for readers to move their eyes back across the page.

Mouse input during an experiment serves three basic functions: (1) it allows the reader to adjust rate of change in the moving window, and thus modulate reading speed; (2) it allows the reader to stop the window and back it up, if some reviewing is desired; and (3) it registers timed responses to overt probes presented, or to information in text which readers are asked to monitor. Rate of change is controlled in a speed-setting mode by moving the mouse. Pushing the mouse away from the reader's body increases speed, and pulling the mouse closer decreases speed. The two other functions respond to input from the mouse buttons. Two of the buttons have been used, for example, to register forced-choice decisions, and the third to permit reviewing. 
Probes to which responses can be timed may be both visual and auditory. Visual probes, such as short questions and probe words, are presented in temporary window areas shown below the current page, or are superimposed over part of the text. For example, in one study (Jarvella, Lundberg, \& Bromley, 1985, Experiment 2), probe words from the text were superimposed over the position that the moving window had just reached, and latencies were measured from the moment the probes became visible. Because the Lisp Machine's screen is fully convertible, black probe windows can be exposed over white page windows and vice versa. Auditory probes have been managed using the Lisp Machine's programmable music.

The text environments in which probes will occur during a text can be marked in text files. Answers to such probes (as well as speed and directional changes) are recorded on-line together with response latencies and, if desired, the contents of the moving window when the behavior occurs. The data are analyzed using normal statistical procedures. By indicating where the reader is at all times, the Textwindow system removes the main obstacle to performing on-line experiments on reading.

The Lisp Machine is not ill-suited to real-time applications. In comparison with other machines, the Lisp Machine is limited in absolute speed and in constancy of runtime for any particular program, but these limitations have not been major problems, for two reasons. First, certain precautionary programming practices, outlined below, can confine slowdowns to noncritical sections of code, thus keeping critical sections running smoothly. Second, the timing tolerances in the work required are loose enough that the capabilities of the Lisp Machine are entirely adequate. In reading research, we are looking for effects on the order of several $10 \mathrm{~s}$ of milliseconds to appear on averages over sizable amounts of data. On the Lisp Machine the individual data (reaction times) are accurate to 1-2 msec. Improved precision may be obtainable in a more conventional computing environment on a faster and more predictable machine; however, such accuracy is beyond our needs.

\section{PROGRAMMING PRECAUTIONS}

For those who are interested in using the Lisp Machine to study reading or a similar process on-line, a few programming precautions are in order. Of the four recommended here, the first two are intended to improve the overall execution speed, and the last two to improve the constancy of runtime for any specific piece of code.

(1) During execution of compiled Lisp code, a relatively large amount of time is used in setting up and returning from function calls, rather than in running the individual functions themselves. One obvious way to circumvent function-calling overhead is to gather the code into a small number of long functions. This method, of course, is very bad programming style and offers no solution. Keeping functions short (essentially limited to one meaningful operation) is extremely important because it allows one to partition a problem into smaller, more easily handled pieces.
There is, however, a way to cut down on function calls in the compiled code without cutting down on the number of functions defined in the source code: by using macros and substitutable functions. With these, the programmer can write and-more importantly-think in terms of a collection of many simple operations, enjoying all the pursuant benefits of modularity, yet having relatively few function calls in the compiled code. Judiciousness, however, is called for. Lumping too many functions together can lead to trouble: If the representation of the resulting function is too large, manipulating the function itself in the course of running it becomes somewhat of a burden on the machine. It is advisable to stick to short, critical sections of code. If such critical sections seem impossible to isolate, the problem probably was not analyzed sufficiently before coding began.

(2) The Lisp Machine graphics facilities can, in fact, be quite slow when accessed via the message-passing mechanism. Many of these messages do, however, have equivalent functions that are much faster. For general use, message-passing is preferable because of its generality and simplicity. But in portions of code in which speed is critical, it is worthwhile to determine the equivalent function and how to use it.

(3) Random delays can occur when the scheduler decides to run a process other than the user process; however, there are several ways to decrease the number and length of these delays. Inessential processes may be arrested so that the scheduler will not waste time considering them. As for processes that cannot be turned off completely because they are needed occasionally (perhaps the screen manager or keyboard processes), the programmer ideally should determine when they will have to run and control scheduling explicitly with such tools as the without-interrupts special form and the process-allowschedule function. If it is impractical to determine when these processes will be needed, they can be fixed to run for less time before relinquishing control back to the user process by reducing their quanta. The quantum of each process (how long it is allowed to run before the scheduler forces it to give others a chance) defaults to a full second, so there is plenty of room for improvement. Note that, for lowered quanta to take effect, the frequency of clock interrupts must be increased by adjusting the meter called "sys: \%tv-clock-rate".

(4) Paging is another potential source of unexpected delays. We have not found it necessary to exercise any control over paging, but such control is readily available. Data structures responsible for troublesome page faults may be paged in or out in their entirety on command, a procedure that takes much less time than handling piecemeal page faults. In extreme cases, the data may be kept permanently in physical memory and never paged out (wired down).

\section{RESEARCH APPLICATIONS}

The Textwindow system currently is being used to study the reading process as it occurs. Here we can refer to some results already obtained (see Jarvella, Lundberg, \& Brom- 
ley, 1985, for further details), and provide a rough basis for comparison with other available techniques.

As far as we have been able to determine, readers using the program can read text accurately and at close to their normal reading speeds. For 16 - to 18 -year-old readers, oral reading rates in the range of $100-300$ words/min have been obtained. Memory measures indicate that the material read can be remembered, with no special instructions required. Measures of reading speed, reading accuracy, and overall comprehension suggest that reading with the present moving window system is quite efficient. Controls carried out with eye recording apparatus further suggest that normal forward saccades and fixations and return sweeps are made with the eyes when moving window text is read. Eye-voice span estimates are 4-5 syllables on average. The Textwindow system prevents the reader from scanning ahead, and limits looking backwards to cases when the reader asks to look back. Except for these restraints, reading in the Textwindow mode appears to take place quite naturally. In Table 1, a summary is presented of comparative data available from one experiment that used the present system and from representative studies that used eye-movement registration, fixed window presentation of sentences and texts (including "rapid serial visual presentation" studies), and other moving window techniques. Reading performance using the Textwindow system compares favorably on measures of both speed and accuracy.

A significant further advantage is that the program is especially suited for combining text presentation with online probe tasks. It has been tested successfully using overt test probes of both an auditory and a visual nature, as well as in a situation in which subjects were asked to monitor text for given information. During noninterrupted reading, subjects have responded to nearly all well-defined targets. Latencies over large sets of data have averaged about $650 \mathrm{msec}$ for choice decisions to simple tones heard while reading, about $500 \mathrm{msec}$ measured from full visibility of 3-5 letter targets when texts are monitored for referents, and about $1 \mathrm{sec}$ in a demanding memory-probe context.

In addition to being a useful tool for performing basic research on reading, the Textwindow system might serve as a vehicle for diagnosing reading problems and assessing text readability. By varying window speed and/or width (four window widths were used in the study referred to at the bottom of Table 1), or by having the reader selfadjust speed, it is possible to obtain a fast and quite reliable estimate of an individual's proficiency in reading. In work already conducted on speed setting, no more than a few minutes of reading appears adequate for this purpose. But it is possible as well to obtain diagnoses of texts themselves,

Table 1

A Comparison of Speed and Off-Line Measures of Understanding in Reading Done Using Eye-Movement Registration and Fixed and Moving Window Methods of Text Presentation

\begin{tabular}{|c|c|c|c|c|c|}
\hline Paradigm Type and Study & Subjects & $\begin{array}{l}\text { Words } \\
\text { Read }\end{array}$ & $\begin{array}{c}\text { Self-Determined } \\
\text { Reading Rate }\end{array}$ & $\begin{array}{c}\% \text { of Free } \\
\text { Reading Rate } \\
\text { (Approximate) }\end{array}$ & $\begin{array}{l}\text { Memory } \\
\text { Measure }\end{array}$ \\
\hline \multicolumn{6}{|l|}{ Eye Movement Recording } \\
\hline Buswell (1920) & 12 & 90 & $\begin{array}{l}235 \text { words/min; } \\
20 \text { letters/sec* }\end{array}$ & & \\
\hline Morton (1964) & 32 & 450 & 230 words/min & & \\
\hline Just \& Carpenter (1980) & 14 & 2,000 & 225 words $/ \mathrm{min}$ & & $31 \%-53 \%$ recall \\
\hline \multicolumn{6}{|l|}{$\begin{array}{l}\text { Fixed Window Systems } \\
\text { manually advanced }\end{array}$} \\
\hline $\begin{array}{l}\text { Aaronson \& Scarborough } \\
\text { (1976) }\end{array}$ & 24 & 1,300 & 150 words/min $\dagger$ & & $92 \%$ true-false \\
\hline $\begin{array}{l}\text { Just, Carpenter, \& } \\
\text { Woolley (1982) }\end{array}$ & 12 & 2,000 & 121 words $/ \mathrm{min}$ & $55 \%$ & \\
\hline \multicolumn{6}{|l|}{ RSVP } \\
\hline $\begin{array}{l}\text { Potter, Kroll, \& Harris } \\
\text { (1980, Experiment 1) }\end{array}$ & 48 & 440 & not determined & & $37 \%$ recall $\ddagger$ \\
\hline $\begin{array}{l}\text { Juola, Ward, \& McNamara } \\
\text { (1982, Experiment 4) }\end{array}$ & 48 & 2,400 & not determined & & $\begin{array}{l}67 \% \text { multiple } \\
\text { choice }\end{array}$ \\
\hline \multicolumn{6}{|l|}{ Moving Window Systems } \\
\hline $\begin{array}{l}\text { McConkie \& Rayner } \\
\text { (1975) }\end{array}$ & 6 & 8,000 & $\begin{array}{l}\text { 14-23 letters/ } \\
\text { sec }\end{array}$ & & $\begin{array}{l}80 \% \text { multiple } \\
\text { choice }\end{array}$ \\
\hline $\begin{array}{l}\text { Just, Carpenter, \& } \\
\text { Woolley (1982) }\end{array}$ & 10 & 2,000 & 136 words $/ \mathrm{min}$ & $60 \%$ & $46 \%-73 \%$ recall \\
\hline Dixon (1984) & 10 & 2,300 & 122 words/min & $75 \%$ & \\
\hline $\begin{array}{l}\text { Textwindow (Jarvella, } \\
\text { Lundberg, \& Bromley, } \\
\text { 1985, Experiment 1) }\end{array}$ & 36 & 3,000 & $\begin{array}{l}195 \text { words } / \mathrm{min} \\
23 \text { letters } / \mathrm{sec} \S\end{array}$ & $90 \%$ & $66 \%$ recall \\
\hline
\end{tabular}

NOTE-RSVP = Rapid serial visual presentation. *High school seniors and college students. †Comprehension instructions (sentences immediately followed by questions). $¥$ Presentation rate of 200 words/ min. §Postexperiment measures. 
by determining at what speed the readers to whom they are addressed can read them. A reader-based text diagnosis would provide a considerably more valid procedure for evaluating text readability than does any existing statistical method.

Our program has been used in several large-scale studies (see also Jarvella, Lundberg, \& Bromley, 1985), but at the present time should be viewed more as a developing system than as a finished product. We hope this report, by pointing out what can be accomplished, will encourage others to develop comparable techniques based around Lisp workstations. A program of the kind described here for the LMI Lisp Machine can also be implemented on the Symbolics 3600 . Less powerful personal computers with mouse capabilities and window systems could perform the more desirable on-line functions incorporated in the Textwindow system at a slower, but still acceptable, speed.

\section{REFERENCES}

Aaronson, D., \& Scarborough, H. S. (1976). Performance models of sentence coding. Joumal of Experimental Psychology: Human Perception and Performance, 5, 675-699.

BUSWELL, G. T. (1920). An experimental study of the eye-voice span in reading (Supplementary Educational Monographs No. 17). Chicago: University of Chicago.

Dixon, P. (1984). A new techrique for measuring word processing time in reading. Behavior Research Methods, Instruments, \& Computers, 16, 109-114.

EJERHED, E., \& ChURCh, K. (1983). Finite state parsing. In F. Karlsson (Ed.), Papers from the Seventh Scandinavian Conference of Lin- guistics (Vol. 2, pp. 410-432). Helsinki: University of Helsinki Department of General Linguistics.

Granaas, M. M., McKay, T. D., Laham, R. D., HuRT, L. D., \& Juola, J. F. (1984). Reading moving text on a CRT screen. Human Factors, 26, 97-104.

IKEDA, M., \& SAIDA, S. (1978). Span of recognition in reading. Vision Research, 18, 83-88.

JARVELLA, R. J. (1979). Immediate memory and discourse processing. In G. H. Bower (Ed.), The psychology of learning and motivation, (Vol. 13, pp. 379-421). New York: Academic Press.

JARVella, R. J., LundBerG, I., \& Bromley, H. J. (1985). Reading in real time. Manuscript submitted for publication.

Juola, J. F., Ward, N. J., \& McNamara, T. (1982). Visual search and reading of rapid serial presentations of letter strings, words, and text. Journal of Experimental Psychology: General, 111, 208-227.

JUST, M. A., \& CARPENTER, P. A. (1980). A theory of reading: from eye fixations to comprehension. Psychological Review, 87, 329-354.

Just, M. A., Carpenter, P. A., \& Woolley, J. D. (1982). Paradigms and processes in reading comprehension. Journal of Experimental Psychology: General, 111, 228-238.

MCConkie, G. W., \& RAYNer, K. (1975). The span of the effective stimulus during a fixation in reading. Perception \& Psychophysics, 17, 578-586.

MORTON, J. (1964). The effects of context upon reading, eye-movements, and the eye-voice span. Quarterly Journal of Experimental Psychology, 16, 340-354.

Newman, E. B. (1966). Speed of reading when the span of letters is restricted. American Journal of Psychology, 79, 272-278.

Potter, M. C., Kroll, J. F., \& Harris, C. (1980). Comprehension and memory in rapid sequential reading. In R. S. Nickerson (Ed.), Attention and performance VIII (pp. 359-418). Hillsdale, NJ: Erlbaum.

Poulton, E. C. (1962). Peripheral vision, refractoriness and eye movements in fast oral reading. British Journal of Psychology, 53, 409-420.

(Manuscript received October 3, 1984; revision accepted for publication March 26, 1985.) 